\title{
Pedagogical Analysis of Police Training Practices in Ghana
}

\author{
Ronald Osei Mensah ${ }^{1} \quad$ Lawrencia Ayim $^{2}$ \\ 1.M.Phil. Graduate, Department of Sociology and Anthropology, University of Cape Coast \\ 2.B.Ed. Graduate, Department of Arts and Social Sciences Education (DASSE), University of Cape Coast
}

\begin{abstract}
This study was embarked upon to do a pedagogical analysis of police training practices in Ghana taking the National Police Training School, Accra and the Winneba Police Command and Staff College, Winneba into perspective. The researcher gathered detailed information about the materials used in teaching and learning at the police training academies and the language (s) used in the teaching and training of trainees at the various police training academies. A total of one-hundred and eighty-eight (188) respondents and participants took part in the study. Questionnaires and interview guide were employed as major data collection instruments. In the data analysis, each of the questionnaires was analyzed using the Statistical Package for the Social Science (SPSS) computer software package (version 20.0 for Microsoft windows) whilst each of the in-depth interviews was transcribed as soon as the information was gathered and developed them into codes. The investigation revealed that materials used in teaching and learning at the police training academies are classified into field materials and classroom materials which are used by recruits and cadet officers differently but akin. The study also revealed that English Language is the sole medium of instruction in the teaching and training at the police training academies. Lastly, the study concluded objectively that lecture method and site visitations were the most informational pedagogical methods used in the teaching and learning at the police training academies. It was therefore concluded that the government through the Ministry of Interior and other stake- holders of the police service must help to provide the needed infrastructure, good facilities, training materials and enough funds to the police training academies to help improve upon the quality of service delivery as well as motivating instructors at the various police training academies across the country.
\end{abstract}

Keywords: Training, Pedagogy, Police Officer, Trainee, Trainer, Recruit, Cadet Officer

DOI: $10.7176 / \mathrm{JEP} / 10-4-08$

\subsection{Introduction}

Training as asserted by Asare-Bediako (2002) involves the development of the person's knowledge, skills and attitude. It is a person's resource developmental activity that is closely related to increasing or maintaining the productivity of trainees. The productivity of trainees is basically informed by the kind of training received by the trainees and the pedagogical practices being used in imparting knowledge.

Training must be encouraged in every organizational setup for the attainment of its aims and objectives. Training, being the tool for the achievement of this objective, is seen as the process whereby people learn the skills, knowledge, attitudes and behaviors needed in order to perform the job effectively. It is seen as a systematic, planned and deliberate intervention aimed at achieving the learning necessary for improved performance (Kenney \& Reid, 1986). Asare-Bediako (2002) explained that trainees must be trained, and where possible, developed to meet their own career needs and the need of the organization. Training is job or task-oriented. It aims at enabling individuals to perform better on the jobs they are currently doing. Organizations must therefore have the responsibility to develop and implement training systems that best help them to achieve their mandates.

Training helps increase upward mobility within the organization to adjust workers to the technological changes affecting the workplace (Asare-Bediako, 2002) of which the police institution is of no exception. The merits of organizational training activities may extend throughout a person's entire career and may help develop the individual for future responsibilities. Training leads to reactions and changes in organizational unit; which therefore leads to the achievement of the ultimate goals of the organization and this is what Talcott Parsons referred to as Goal attainment (Parsons, 1951) as cited in (Graham \& Marvin, 2002). That is the goals of societies and social institutions have to be defined, resolving goal conflicts, prioritizing some over others, determining resource allocations and directing social energies.

The purpose of police training is to provide officers with a level of understanding that will allow them to effectively employ problem-solving and community engagement techniques in their daily work. This can be done effectively when the right pedagogical methods are explored. With this, the right goals and expected results would be achieved (Peak \& Glensor, 1999). Other attempts to improve or reform the police have often relied upon new or improved training (Buerger, 1998; Fogelson, 1977).

Training is said to be an integrative system, this is because various people with different expertise and pedagogical practices are needed to bring their skills on board to enhance training efficiency and effectiveness and the expected standards and social outcomes (Mensah, 2019). Hence the call for this study to do a thorough pedagogical analysis of police training practices. 


\subsection{Statement of the problem}

The discussion above points to one fact, which are the various pedagogical practices used in the police training academies. Some of these pedagogical practices may come in the form of the lecture methods being used, the medium of instruction used in teaching and learning and the materials used in the teaching and learning of trainees and cadet officers.

A huge component of complaints to the Commission for Human Rights and Administrative Justice (CHRAJ) deal with Police misconduct. Reforming those institutions without corresponding review in its pedagogy through relevant training will be very sub-optimal (Atuguba, 2007). It has been revealed that most members of the police organisation do not even have access to basic documents, such as the Constitution, the Police Service Act or the Police Service Instructions (Corston, 2007). Police in Ghana have continued to use rubber bullets and water cannons in crowd control situations (Lamb, 1995). Some of these negative outcomes have resulted in low public confidence and bad reputation of the police service. All these pose a lot of questions in one's mind concerning the kind of training and the pedagogical practices police officers in Ghana go through and use before they are finally recruited into the service.

Despite the fact that some studies have been done on police training practices, previous research has not been able to explore critically into the pedagogical practices employed by police trainers in the training academies in order to really assess the training practices and outcomes of these officers and trainees respectively. As a result, it has worsened the challenges faced by police officers in their work delivery and the Ghana Police Service as a whole. On the other hand, if the right pedagogical practices are employed and strictly followed, the right application of the law and police equipment will be in proper place. This leads us to the objectives of the study.

\subsection{Objectives}

The study generally aims to do a pedagogical analysis of Police Training Practices in Ghana at the National Police Training School (NPTS) and the Winneba Command and Staff College (WPCSC)

\subsection{Specific Objectives}

The study specifically aims to:

1. find out the materials used in teaching and learning at the police training academies

2. find out the language (s) used by instructors in the teaching and training of police officers

\subsection{Research Questions}

1. What are the materials used in teaching and learning at the police training academies?

2. What language (s) is used by instructors in the teaching and training of police officers?

\subsection{Significance of the study}

The outcome of this study will add to the existing knowledge on police pedagogical practices and training. The study goes further to find out the materials used in teaching and learning at the police training academies and the language (s) used by instructors in the teaching and training of police officers. This will go a long way to help the police administration especially police officers and instructors at the various training academies across the country. The study finally serves as a source of theoretical and empirical literature to any individual or institution for the purpose of further research on the subject or other related areas.

\subsection{Definition of Operational Terms}

Training: Ongoing processes of helping employees perform a particular work. That is, a person's skills and competences are improved to do a particular job or accomplish a specified task.

Training Practices: The methods which are used by trainers as an aid to provide trainees with the necessary skills and abilities needed to execute or perform a job.

Pedagogy: The method and practice of teaching. With this study, the teaching methods focuses on the lecturers who teach at the training academies in terms of their qualifications, student-lecturer interaction, the language used in teaching at the academy and the various methods used in the execution of training.

Police Officer: A person employed by government, trained in methods of law enforcement, crime prevention and detection and authorized to maintain the peace, safety and order of the community.

Trainee: A person being trained in a particular job in order to learn the skills needed for that job. That person is mostly termed as a learner.

Trainer: A person who trains or teaches the needed skills to people and prepares them for a job or activity

Recruit: A person newly enlisted in the 'police training school' and not fully trained or an entry level position that do not have much experience yet to be commissioned as a junior police officer.

Cadet Officer: Is a rank held by a person who is a training to become commissioned officers. They are normally referred to as junior trainees. 


\subsection{Literature Review}

\subsection{Concept of Training}

Training is an excellent way for the police to learn new skills and practices and to adopt new practices. However, to achieve success in police training, it depends on the available opportunities that will help the knowledge and skills to perform a specific activity to be acquired (Reid, 1996).

Adarkwa (2001) refers to training as a planned activity that aims at fulfilling challenges in the individual or group of people concerning their knowledge and skills. According to De Silva (1997), training is the transferring of information and knowledge to employees. He also stressed that training should be considered along with education policies and systems which are crucial to the development of human resources in an organization. From the above explanations, it is imperative for the police to have a well-defined and structured curriculum (Mensah, 2018) as well as pedagogy which would be used in the process of training and learning.

Donnelly, Dalal-Clayton and Hughes (1998), termed training as an ongoing process of helping employees perform a particular work from the day they start work. That is, training is designed to improve a person's skills and competences to do a particular job. For training to be effective, it must follow certain criteria or accomplish a certain number of goals with the support of the right pedagogical skills. For example, recruits pass through a number of steps or criteria before they are finally sworn into office as police officers.

\subsection{The Philosophy Informing Police Training Programme}

Philosophy of the training programme talks about the idea or motive behind police training. According to Currie (2004), organizations initiate training programmes for many different reasons. The strongest motive of training is the need to respond to challenges represented by new technologies or current trends. According to Alder (1996); Machold and Fishell (2005); Wang, Shan, Shasha, and Piel (2005), recruiting and selecting of applicants to be trained as police officers is an extremely important part of the administrative duties of police departments and that when an individual is selected for employment in the police department, then the department is making a long term investment in that individual. Reid (1996) also recommended a classroom training work spread over a period of four to six months so that it can carefully be combined with a selected and supervised training on the field. She also recommended a lot of in-service training at least once a year along with other incentives to encourage and motivate serving officers to pursue higher education.

In a country like Ghana, training in the Police Service is very important because it makes the government and the Police force respond to current socio-economic trends and reacts to the increasing crime rate in some parts of the economy. Also, in striving to enhance efficiency and level of performance, training should be seen as part of the individual professional development. The Police institution will only enhance the capability of its staff if it only invests in training. This will help the Police force gain new skills and capabilities in executing their day to day activities. However, the social-learning model and learning principles tell us that training should provide the trainee with a given model to follow specific goals to achieve, an opportunity to perfect the skill, feedback on how well the trainee is progressing, and place for transferring the skills to the job with the right and appropriate pedagogical skills.

It is abundantly clear that adequate performance in all areas of policing requires information on specially selected, specially trained, what type of education and how much education on training these personnel require (Cox, 1996).

From the discussion, the motive behind training in an institution is the need to respond to challenges represented by new technologies or current trends and also it is very true that when an individual is selected for employment in the police service is a long-term investment because the individual in the service commits his or her whole lifetime to work for the service except in critical conditions. That is why this study aims to find out the pedagogical practices employed at the various police training academies.

\subsection{Pedagogical practices at the Ghana Police Training Academies}

The pedagogy is teacher-centered and structured, and it relies heavily on a lecture format (often referred to by trainees as "talking heads"). Promoters of innovative training programs recognize that police recruits not only need to learn the traditional skills of policing (e.g. officer safety, mechanics of arrest, marksmanship), but they need a comparable amount of training in such subjects as problem solving, diversity and communications (Bradford \& Pynes, 1999).

During the latter part of 1943, the whole training programme for the General police was revised. An attempt was made to cut down "Lecturing" and to replace much of it with practical work. Written examinations were reduced and practical oral tests increased. All recruits had to pass such subjects as keeping station diary, traffic signals, telephone duty, note book keeping and taking fingerprints, among others. First Aid course was organized and examinations were held after each course (Annual Report on the Gold Coast, 1951) as cited in (Pokoo- Aikins, 2009).

The Drill instructors in the service were all members of the Escort Branch. However, only experienced and 
qualified certificated personnel were appointed to become instructors of the police training depots. Special lectures were given by Senior Police Officers (SPOs) and special lectures by visiting lecturers from other Government Department and Organizations. Firefighting was included as a subject in the mid-1960s (Annual Report of the Ghana Police Service, 1960).

In the Ghana Police College, the pedagogical principles on which tuition is based may be said to be the inherited British system with local adaptations. It is the system to which students are accustomed. Theory is taught in the classroom and practical work by demonstration and exercise "on the ground". Classroom instruction involves the use of the blackboard and other teaching aids. The language of instruction is solely English. Students take notes of lectures which they later transcribe and amplify into their permanent record books. Lecture notes (Handouts) on all important subjects are circulated to the students who file and retain them as a permanent record. Wide use is made of class syndicated, discussion and study groups (Annual Report of the Ghana Police Service, 1960).

Staff instructors are carefully selected on the basis of past performance and experience, teaching ability, interest in imparting instruction and personal qualities. In all officers training, the students are taught how to lecture and impart instruction and how to use teaching aids. Those who distinguish themselves in this field are earmarked as potential instructors and given further training when necessary. Visiting lecturers, that is, senior officers and specialist officers from the service and outside lecturers from other universities, Government departments and specialized institutions were, and are still employed when the student population was increased and more liberal subjects were introduced (Annual Report of the Ghana Police Service, 1960).

Staff instructors that are selected on the basis of experience and past performance and not on qualification or terminal degrees has its own negative effects on the depth of knowledge acquired and the results expected. When experienced men are engaged to teach trainees because of their past performance, trainees in the end might do well in the practical aspect but might be lacking when it comes to the theoretical acquisition of knowledge and its adverse effect on output and vice versa.

The Senior Officers courses run at the police college are handled by the commandant and his team of staff instructors at the college. In addition to the permanent teaching staff at the college, a large number of visiting lecturers, made up of experienced Senior Police Officers (SPO's) with relevant academic/professional qualifications and experience in specific disciplines, professors and lecturers from the University of Ghana, Accra and the Ghana Institution of Management and Public Administration (GIMPA), are engaged to assist with instruction at the college. Courses run by GIMPA are mostly taught by the institute's own professional teaching staff, with occasional lectures delivered by very Senior Police Officers in specific subjects areas (Pokoo-Aikins, 2009).

From the above, the researcher would like to add that, training of trainees into policing should be more practical-centered than theory-centered as Bradford and Pynes (1999) suggested. This will help officers to be able to apply whatever they are being taught practically. All these go a long way to bring about effective policing. Hence, the call for this study

\subsection{Training Methods in Police Service}

Armstrong (2001) asserted that, training methods are crucial to the success of organizational training programmes. The only general rules for conducting training programme are that, first, the courses should continually be mentioned to ensure that they are proceeding according to the plan and within the agreed budget and second, all training should be assessed after the event to check on the extent to which it is delivering the required results. This is the job of the one who has the responsibility for trainee development, which should be required to report on progress against plan at regular intervals for the development of trainees and the organisation.

There are, however, a number of considerations that affect the conduction of training for special occupations. Special approaches may be used for particular group of trainees. In Armstrong's view technical and skills or craft training scheme can be divided into four main types and these are; Graduate - postgraduate training leading to a professional qualification, Student - a course of education and practical training leading to a degree or some other qualification as an engineer, scientist and technologist or technician, Technician - a course of education and training, which could last up to three or four years, leading to empowerment as a technician and an appropriate technician's qualification. Skill and Craft -a course lasting a number of years, depending on the level of skill that has to be attained and often leading to a craft certificate or other record of achieved (Armstrong 2001)

Armstrong (2001) mentioned that there are three phases of skill training. First of all is Basic training. Trainees received training in basic skills in a basic training workshop. These training should consist of a series of modules. Clearly, the standard modules should be chosen on the basis of an analysis of the skills required, and additional modules should be specifically developed if necessary. In every organisation or institution like the Ghana Police Service, most trainees are taken through basic training. This helps trainees to understand certain basic issues in the organisation if they are newly placed on the job and solve simple problems. The Ghana Police Service normally gives basic training to its members when trainees are in the various police training schools. 
Secondly, General trainees are given experience in a number of different departments, processes or operations to consolidate training. This helps trainees to be versatile in all approach of their work and enhances their effectiveness.

Last of these phases is Final training. Trainees settle down in the department of their choice, or the department of which they are best fitted. The aim is to ensure that they are equipped to apply their learning in normal working conditions and at the pace and level of quality expected from a fully experienced and competent individual. This helps trainees to best fit at wherever they are placed on the job.

According to Robbins and Coulter (2002) managers or institutional heads are responsible for deciding what type of training employees need, when they need it, and what form that training should take. They further grouped employees skills into three categories; technical (these include basic skills - the ability to read, write and do mathematical computations as well as job - specific competencies), interpersonal (this often include learning how to be a better listener, how to communicate ideas more clearly and how to reduce conflict, and problems solving (when the skills of employees are deficient, manager might want to improve them through training).

All these help trainees to participate in activities that will sharpen logic, reasoning, and skills at defining problem) hence, effectiveness of their training program. However, their view on training methods state that most training takes place on the job because this approach is simply to implement and is usually inexpensive. Beside, on - the job training can disrupt the workplace and result in an increase in an error whiles the learning process take place. In all, when trainees are successfully taken through effective training methods, there will be efficiency resulting from police training practices and likely expected outcomes (Mensah, 2019). These training methods can be referred to as pedagogical practices.

\subsection{Research Methodology}

This study is about the pedagogical practices employed by police trainers in the police training academies. This study goes further in detailing the materials used in teaching and learning at the police training academies and the language (s) used by instructors or police trainers in the teaching and training of police trainees.

\subsection{Research Design}

Creswell (2009) also defined research design as a procedure enquiring into a study that spans the decision from broad to detailed method of data collection and analysis. This study made use of descriptive research design. The researcher documented enough information that enabled him to effectively describe the problem. This study is a descriptive study because it aims to find out the pedagogical practices employed by police trainers in the police training academies.

\subsection{Study Area}

The study aims to find out the various pedagogical practices employed by police trainers at the police training academies in the teaching and learning of trainees at the National Police Training School (NPTS), Accra and the Winneba Police Command and Staff College (WPCSC) at Winneba. The National Police Training School was chosen because it commands all other depots, it can recruit sixty recruits at a time, and it is a place that trains both sexes, both junior rank officers and senior rank officers. Most of the officers are staying on the premises of the NPTS, and lastly, it is equipped with all the facilities needed for training recruits. The NPTS is therefore the researchers' main area of concentration.

Winneba Police Command and Staff College (WPCSC) was also chosen to support this study because it is one of the newest police training depots in Ghana for training Senior Officers (SPOs). It has the modern training facilities and also closest to the researcher's institution.

\subsection{Population}

The population comprises of both males and females with basic education and with some higher education. Some of these people are with secondary school certificate, diploma, professional certificate, first degree and others with master's degree. These people have various rankings like constable, corporal, sergeant, inspectors, chief inspectors, assistant superintendent, deputy superintendent, superintendent and chief superintendent. The estimated size of the population is 188 comprising of trainees, trainers and officers who have undergone the training programme already.

\subsection{Sample size determination of Trainees}

A sample is a finite part of a statistical population whose properties are studied to gain information about the whole (Webster, 1985). Slovin's formula was adopted to set limit for the number of trainees to be selected from the National Police Training School. The Slovin's formula is

$$
n=\frac{N}{1+N e^{2}}
$$

Where: $\mathrm{n}=$ the sample size, $\mathrm{N}=$ sample frame or the target population and $\mathrm{e}=$ Degree of freedom with a margin 
error of 0.05 (confidence level of $95 \%$ ). If the total number of trainees is 153 and it is substituted into the formula, mathematically the number of trainees to be interviewed would be calculated as $n=153 / 1+153(0.05)^{2}=110.67$ to the nearest decimal is 111 . Therefore the number of respondents to be selected as trainees from the National Police training academy is 111 whilst the respondents to be selected as trainees from the Winneba Police Command and Staff College are 33. This is because the researchers had 33 as the whole population for senior officers at the Winneba Police Command and Staff College (WPCSC) and were interviewed by administering questionnaires to them through the simple random sampling technique.

\subsection{Total sampling size for the study}

Total number of people who participated in the study is captured in table 1 below:

Table 1- Sample Technique and Size for the Study

\begin{tabular}{lll}
\hline Respondents for quantitative data & Sampling technique & Number \\
\hline Trainers/ instructors (NPTS/WPCSC) & Simple Random & 20 \\
Trainees (NPTS) & Simple Random & 111 \\
Trainees (WPCSC) & Simple Random & 33 \\
Officers who have undergone the training programme (NPTS/WPCSC) & Simple Random & 20 \\
\hline Participants for qualitative data & & \\
\hline Commandant of the NPTS & Purposive & 1 \\
Administrators (NPTS/WPCSC) & Purposive & 3 \\
Total & & 188 \\
\hline
\end{tabular}

\subsection{Data Collection Instruments}

Instruments for data collection were both quantitative and qualitative. Quantitative data collection instruments were questionnaires whereas qualitative instrument was an interview guide. The quantitative data collection instrument which were questionnaires were used to elicit data from trainees of the police training schools, the trainers or instructors and the police officers who have already undergone the training programme whereas the qualitative data collection instrument which was the interview guide was used to elicit data from the administrators of the training schools and some key informants like the commandant of the training school, some staff commanders and instructors as well.

The questionnaires used in the study were very appropriate because it answered the research questions of the study and also the instruments helped the researcher to present details of the various pedagogical practices in the training academies.

Primary sources of information were elicited through structured interviews with some trainees at the Winneba Police Command and Staff College and the National Police Training School, trainers or instructors at the college and some officers who have undergone the training programme were interviewed in order to know their experience. The Commandant of the National Police Training School (NPTS) was also interviewed to find out the pedagogical practices employed at the college. Some face-face interviews were conducted with the administrators and some departmental heads of the training school to find out the materials used in teaching and learning at the police training academies and the language (s) used in teaching and learning at the police training academies to enhance effective police training practices.

\subsection{Sources of Data}

Sources of data for the study were both primary and secondary. Secondary sources were books related to the area, research journals and any other source(s) which was relevant to the purpose of the study. The research unit of the Ghana Police Service (GPS), Headquarters, Accra was consulted for some information pertaining to police training practices.

\subsection{Data Processing and Analysis}

The data collected was edited, coded and analyzed. The quantitative data that was generated by the study was processed and analyzed using Statistical Package for the Social Science (SPSS) computer software package (version 20.0 for Microsoft windows). Findings from the analysis were presented in contingency tables with summary statistics.

\subsection{Ethical Considerations}

Since the police institution is a sensitive one, anonymity and confidentiality were strictly followed.

\subsection{Limitations of the Study}

In the course of the data collection, the researcher encountered some problems.

First of all, a major hindrance to the study during data collection was that questionnaires were sent on time 
but were not handed over on time to the researcher by the respondents at the National Police Training School (NPTS) in Accra. Some respondents also refused to be audio-taped, the reason being that their voice could easily be identified. This meant that the researcher had to take a lot of notes and this hampered the smooth pace and flow of the interview process.

Secondly, most interviewees were very skeptical in providing information to the researcher because most of them taught the answers they give might be used against them by querying or even dismissing them but this challenge was overcome by reassuring them of utmost confidentiality and anonymity.

Thirdly, information about police training practices was not much available to the researcher so the researcher had to move from one place to the other and conduct in-depth interviews before getting some of the vital information he needed.

Fourthly, the researcher found it difficult meeting up with his respondents due to assignments and tight schedules by personnel of the Ghana Police Service (GPS).

In addition, language barrier was also a problem. In the sense that, some respondents did not understand some of the key terms that were used in the questionnaire so the researcher had to find time meeting with respondents to explain these key terms in the questionnaire to them.

Lastly, law enforcement duty required certain procedures to be followed to gain the right kind of information and this made the project very stressful. Some of the police officers were not willing to answer the questions because they said they will not benefit from responding or perhaps even be penalized for giving their real opinion.

\subsection{Data Analysis and Discussion}

Research Objective One: To find out the materials used in teaching and learning at the police training academies

The researcher was adequately informed by trainers, trainees and police officers of the National Police Training that materials for teaching and learning are classified under classroom materials and field materials. Classroom materials are the items, tools and other relevant equipment which are used during classroom delivery whereas field materials are gadgets and equipment used while trainees or learners are outside the classroom. Materials used for recruits differ from materials used for cadet officers in the teaching and learning. Some of the materials are common to both schools. Table 2 and 3 clearly depicts that:

Table 2-Materials used in Teaching and Learning at the Police Training School for recruits

\begin{tabular}{ll}
\hline Classroom materials & Field materials \\
\hline Projectors & AK 47/ Rifles \\
Whiteboard & Investigation kits \\
Markers & Ammunitions \\
Flippers & Firearms \\
Textbooks/ handouts & Cutlass \\
Modules/ Power Points & T-Batons \\
Computers & Communication gadgets \\
Criminal law and procedure books & Bucket \\
Squad notes & Broom \\
Acts and decrees & Shield and truncheon \\
Service instructions & Tear gas \\
The constitution & Canvass \\
Criminal code book & Pistol \\
Service instruction book & Mark 4 \\
Exercise books & Handcuff \\
Pens and rulers & Vehicles \\
Flip chart & Pole sticks \\
Tablet & \\
Teaching syllabus & \\
T-shirts & \\
Rulers & \\
Room syndicated discussion & \\
Audio and visual & \\
\hline
\end{tabular}


Table 3-Materials used in Teaching and Learning at the Police Academies for cadet officers

\begin{tabular}{ll}
\hline Classroom materials & Field materials \\
\hline Service instructions & Arms and ammunitions \\
Law books & T-baton \\
White board & Truncheon \\
Projectors & Handcuffs \\
Markers & AK 47 rifles \\
Flippers & Firearms \\
Police squad notes & Pole sticks \\
Acts and decrees & \\
The constitution & \\
Tablet & \\
Criminal code book & \\
Flip chart & \\
Room syndicated discussion & \\
Audio and visual & \\
Criminal law and procedure book & \\
Modules/PowerPoint & \\
Tablet & \\
Legislative and constitutional instruments & \\
\hline
\end{tabular}

The materials used in teaching and learning at the police training schools explain Talcott Parson's theory of adaptation. Adaptation as explained by Parson's means securing from the environment (Parsons, 1961). The materials police trainees use in teaching and learning like projectors, the criminal code book, room syndicated discussion, squad notes, flippers, rifles, pistol, handcuff, shield and truncheon is a way in which police trainees also learn. In the end, appropriate knowledge is secured by these police trainees who inform police training practices. If police trainees apply whatever is taught them very well, they will be able to integrate whatever they have learnt into their day to day activities in the police service and by so doing achieving both the core and noncore function of the Ghana Police Service hence Goal Attainment (Parsons, 1951). When all these materials are effectively used, police training practices would also yield its results positively and effectively.

It can therefore be concluded that the materials used at the police training schools for recruits differ from materials used at the police academies for cadet officers. This is because cadet officers pass out as senior officers after the training exercise whilst recruits pass out as junior officers hence difference in training methods and materials.

\section{Language (s) used by instructors in the training}

In line with the pedagogical practices employed by police trainers at the police training academies, the researcher sought to find out the language mostly used by instructors in the teaching and learning of trainees. Table 4 below shows that.

Table 4- Language (s) used by Instructors in the Training

\begin{tabular}{lcccc}
\hline Variables & Police Officers & $\begin{array}{c}\text { Winneba Trainees } \\
\text { (cadet officers) } \\
\text { F }(\%)\end{array}$ & $\begin{array}{c}\text { Accra Trainees } \\
\text { (recruits) }\end{array}$ & Trainers \\
\hline English & $\mathrm{F}(\%)$ & $29(87.9)$ & $\mathrm{F}(\%)$ & $\mathrm{F}(\%)$ \\
Twi & $18(90.0)$ & $3(9.1)$ & $24(21.6)$ & $18(90.0)$ \\
French & 0 & $1(3.0)$ & $12(10.8)$ & $2(10.0)$ \\
\hline
\end{tabular}

Among the police officers, $90 \%$ of the police officers indicated English language as the medium of instruction whereas $10 \%$ indicated French as the medium of instruction. $87.9 \%$ of the Winneba trainees indicated English to be the medium of communication whereas $9.1 \%$ indicated Twi. Furthermore, majority of the trainees from the National Police Training School (NPTS) representing 64.8\% indicated that English is the medium of instruction at the police training followed by $21.6 \%$ representing Twi as the medium of instruction. Lastly, $90 \%$ of trainers at the NPTS indicated that English is the medium of instruction whereas $10 \%$ indicated Twi as the medium of instruction. It can therefore be concluded that English is the prime language that serves as a medium of instruction at the police training academies. This confirms what was indicated earlier in the literature from the Annual report of the Ghana Police Service (1960) that English is the sole language which serves as a medium of instruction in the Ghana Police training academies. This will help police officers break the front and interact meaningfully to all wide range of persons in the course of their duties especially when it comes to issues affecting neighbouring and outside countries. 
Table 5- The Various Pedagogical (Teaching Methods) Practices

\begin{tabular}{lccc}
\hline Variables & $\begin{array}{c}\text { Winneba Trainees } \\
\text { (cadet officers) }\end{array}$ & $\begin{array}{c}\text { Accra trainees } \\
\text { (recruits) }\end{array}$ & Trainers \\
& F (\%) & F (\%) & F (\%) \\
\hline Lecture Method & $1(5.0)$ & $32(28.8)$ & $5(25.0)$ \\
Guest lectures & $8(40.0)$ & $20(18.0)$ & $2(10.0)$ \\
Technology-Based Lectures & $6(30.0)$ & $30(27.0)$ & $2(10.0)$ \\
Practical (Hands on) & $3(15.0)$ & $19(17.0)$ & $5(25.0)$ \\
Site visitations & $2(10.0)$ & $10(9.0)$ & $6(30.0)$ \\
\hline
\end{tabular}

With the various pedagogical practices, $40 \%$ of the trainees from Winneba Police training school were of the view that guest lectures was used frequently in their teaching followed by technology based lectures representing $30 \%$ and the least was the lecture method representing 5\%. According to trainees form the National Police Training School, it came to light that $28.8 \%$ said that lecture method was frequently used followed by technology based lectures representing $27 \%$ whilst the least is $9 \%$ representing site visitations. The trainers at the NPTS also were of the view that site visitations were mostly used representing $30 \%$, whilst practical (hands on) and lecture method represented $25 \%$ each respectively.

It can be concluded that guest lectures, lecture method and site visitations are the main pedagogical practices that were mostly adopted in the teaching and learning of trainees that is both the recruits and cadet officers. This implies that guest lectures, lecture method and site visitations are the mostly used methods in police training academies in Ghana. Sociologically, it can be said of that guest lectures, lecture method and site visitations are the most effective and efficient pedagogical practices which is helping the police service in the fulfillment of their academic pursuit at the various police training schools.

\subsection{Conclusions}

\section{Materials Used in Teaching and Learning at the Police Training Academies}

It can be accurately concluded that, the materials used in teaching and learning at the police training academies are classified into field materials and classroom materials. Police recruits at the National Police Training School (NPTS) have their own training materials which is distinct but similar to that of the cadet officers at the Winneba Police Command and Staff College (WPCSC)

\section{Language (s) Used by Instructors in the Teaching and Training of Police officers}

It has been deduced from the study that the most effective teaching and learning method that is used by the police training academies is classroom instruction which is solely delivered in English Language as the medium of instruction. This means that classroom instruction had a greater impact in the teaching delivery process with English as the dominant language of interaction because this is a language which cuts across every sector in the country and in international operations as well.

\section{Pedagogical Practices employed at the Police Training Academies}

It has also been deduced that lecture method and site visitations had the largest impact on trainees learning. Also, it was observed that most of the respondents took within 6-8 months to complete their training programme with a good student-lecturer relationship at the training academies. This implies that lecture method and site visitations were the most informational method which was used by trainees and trainers in teaching and learning with six months period of training which is considered very satisfactory to train recruits and cadet officers in becoming security officers of the state.

\subsection{Recommendations}

1. The government through the Ministry of Interior and other stake- holders of the police service must help to provide the needed infrastructure, good facilities, training materials and enough funds to the police training academies to help improve upon the quality of service delivery.

2. The government, through the Ministry of Interior, must encourage and motivate the authorities in the various police training institutions as well as the police service in general for the professional ways in which they apply their training skills in maintaining law and order in the country.

3. The government and the other stakeholders, through parliament, must help to enact a law or device a code of conduct that will reduce or eliminate political interference during recruits' selection period. This will help produce quality and deserving graduates from the police service who will deliver expectably.

4. In order to empower the police agencies to properly use the computer and other forms of technology in their daily operations, the government in collaboration with the Ministry of the Interior through the Police administration should establish a progressive capacity building programmes for officers and trainees to acquire new skills and effective ways of enforcing law and order and to be abreast with changing environment. 


\section{References}

Adarkwa, K. K. (2001). Social and economic infrastructure for rapid growth and sustainable development in Ghana. Institute of Statistical, Social \& Economic Research, University of Ghana.

Alder, J. (1996). Have tropical marine protected areas worked? An initial analysis of their success. Coastal Management, 24(2), 97-114.

Annual Report of the Ghana Police Service. (1960).

Annual Report on the Gold Coast Police. (1951).

Armstrong, M. (2001). A handbook of management techniques: The best-selling guide to modern management methods. New York: Kogan Page Publishers.

Asare-Bediako, K. (2002). Professional skills in human resource management. Accra: Kasbed Ltd.

Atuguba, R. (2007). The Ghana Police Service (GPS): A practical agenda for reform. Institute of Economic Affairs. Policy Analysis, 3(1).

Bradford, D., \& Pynes, J. E. (1999). Police academy training: why hasn't it kept up with practice? Police Quarterly, 2(3), 283-301.

Buerger, M. E. (1998). Police training as a Pentecost: Using tools singularly ill-suited to the purpose of reform. Police Quarterly, 1(1), 27-63.

Corston, J. (2007). The corston report. London: Home Office.

Cox, S. M. (1996). Police: Practices, perspective and problems. Boston: Allyn and Bacon.

Creswell, J. W. (2009). Research design: Qualitative and mixed methods approaches. London and Thousand Oaks: Sage Publications.

Currie, J. (2004). The take up of social benefits. National Bureau of Economic Research. Retrieved from http://www.nber.org/papers/w10488

De Silva, S. (1997). The changing focus of industrial relations and human resource management. International Labour Organisation Publication.

Donnelly, A., Dalal-Clayton, D. B., \& Hughes, R. (1998). A directory of impact assessment guidelines. IIED. Retrieved from https://books.google.com/books

Fogelson, R. M. (1977). Big-city police. Harvard: Harvard University Press.

Graham, S., \& Marvin, S. (2002). Telecommunications and the city: Electronic spaces, urban places. Routledge. Retrieved from https://books.google.com/books?hl=en\&lr=\&id=saKHAgAAQBAJ\&oi=fnd\&pg=PP1\&dq=

Kenney, J., \& Reid, M. (1986). Training interventions. London: Institute of Personnel Management.

Lamb, C. (1995). Non-Lethal weapons policy: Department of Defense Directive.

Machold, R., \& Fishell, G. (2005). Math is expressed in temporally discrete pools of cerebellar rhombic-lip neural progenitors. Neuron, 48(1), 17-24.

Mensah, R. O. (2018). Assessment of training practices in the Ghana Police Service. Journal of Law, Policy and Globalization, 79, 265-273.

Mensah, R. O. (2019). Social outcomes of training practices in the Ghana Police Service. Research on Humanities and Social Sciences, 9, 69-82.

Parsons, T. (1951). Social structure and dynamic process: The case of modern medical practice. Retrieved from https://repository.library.george town.edu/handle/10822/762066

Parsons, T. (1961). Theories of society. Free Press of Glencoe.

Peak, K. J., \& Glensor, R. W. (1999). Community policing and problem solving: Strategies and practices. Prentice New Jersey: Prentice Hall.

Pokoo-Aikins, J. B. (2009). The police in Ghana, 1939-1999. Pokoo-Aikins.

Reid, L. D. (1996). Dynamics of flight: stability and control (3 ${ }^{\text {rd }}$ ed.). New York: Wiley.

Robbins, S. P., \& Coulter, M. (2002). Management. New Jersey: Pearson.

Wang, J. T., Shan, H., Shasha, D., \& Piel, W. H. (2005). Fast structural search in phylogenetic databases. Retrieved fromhttp://search.proquest.com/openview.

Webster, R. (1985). Quantitative spatial analysis of soil in the field. Retrieved from http://link.springer.com/chapter 